\title{
Formação Omnilateral Docente e a Mercantilização de Eventos Acadêmicos e Científicos da Área de Educação
}

\section{Omnilateral Teacher Training and the Academic and Scientific Events Commodification in Education Area}

\author{
DOI: $10.46814 / \operatorname{lajdv3n4-053}$
}

Recebimento dos originais: 01/05/2021

Aceitação para publicação: 31/06/2021

\section{Isabelly Raiane Silva dos Santos}

Mestranda em Letras pelo Programa de Pós-graduação em Letras (PPGL) da Universidade Federal do Pará (UFPA)

Docente no Instituto Federal de Educação, Ciência e Tecnologia do Pará (IFPA)

Endereço institucional: Rodovia Ernesto Acyoli, S/N, Km 3 - Nova Colina, Altamira-PA, Brasil

E-mail: isabelly.santos@ifpa.edu.br

\section{RESUMO}

Defende-se que formação de professores, além de ser continuada, deve apresentar um caráter contínuo. $\mathrm{Na}$ procura por essa formação, docentes buscam a participação em cursos e eventos acadêmicos e científicos. Entretanto, a partir do avanço do Toyotismo e da aprendizagem flexível, eventos, como congressos, têm sua realização motivada por aspectos do capital. A partir disso, os objetivos dessa pesquisa são investigar a relação estabelecida entre a execução de eventos acadêmicos e científicos e a mercantilização da educação, expor situações que evidenciem a ideologia do capital presente na execução de um evento acadêmico e científico e indicar pontos relevantes do evento que poderiam contribuir para a superação do docente acrítico e fragmentado pelo capitalismo. Dados foram coletados a partir da análise da organização e execução de um congresso. Ao final, foi verificado que, embora guiado por aspirações capitalistas, eventos, como o analisado, podem constituir uma forma de superação do docente unilateral.

Palavras-chave: Formação docente, Mercantilização da educação, Aprendizagem flexível.

\begin{abstract}
It is argued that teacher training, besides being continuous, must have an ongoing character. In the search for this training, teachers seek participation in courses and academic and scientific events. However, from the advance of Toyotism and flexible learning, events, such as congresses, have their realization motivated by aspects of capital. From this, this research's objectives are to investigate the relationship established between the execution of academic and scientific events and the education commodification, to expose situations that show the capital ideology present in the execution of an academic and scientific event, and to indicate relevant points of the event that could contribute to overcoming the uncritical and fragmented teacher by capitalism. Data were collected from the analysis of a congress organization and execution. In the end, it was found that, although guided by capitalist aspirations, events, such as the one analyzed, can constitute a way of overcoming the unilateral teacher.
\end{abstract}

Keywords: Teacher training, Education commodification, Flexible learning. 


\section{INTRODUÇÃO}

A formação docente, muitas vezes analisada unicamente sob a ótica do viés continuado, necessita ser fomentada a partir do viés contínuo. Isso significa que a constituição do professor não é resultado apenas da educação em espaços formais, como a escola e a universidade. Por isso, é válido que a formação, ao invés de focar apenas no aspecto continuado, foque no aspecto contínuo (MOURA, 2014). A formação contínua pode ser realizada por meio de diversas maneiras: cursos de graduação e pós-graduação, cursos de aperfeiçoamento, cursos de formação inicial e continuada, e participação em eventos acadêmicos e científicos, por exemplo.

Nesse contexto, diante das restrições, principalmente de circulação, impostas à população devido à pandemia instaurada pela COVID-19, uma doença infecciosa causada por um vírus recémdescoberto, verifica-se diversas modificações na morfologia das oportunidades de formação de professores. Dentre elas, destaca-se o modo como os eventos acadêmicos e científicos, como congressos, encontros, simpósios, conferências, oficinas e minicursos vêm se configurando. Assim, essa configuração, a realização de eventos online, que já existia de modo restrito e minimalista, ganhou maior destaque no cenário atual.

Nos últimos anos, a formação de professores tem sido alvo de discussões. Essas estão rodeadas por diversas ideologias. Nessa conjuntura, duas vertentes se destacam: a primeira, hegemônica, tem suas bases no capitalismo e é sustentada pela alienação do ser humano e de sua força trabalho, garantindo, com isso, a reprodução da ideologia desumanizadora do capital cada vez mais presente na sociedade (MOURA, 2014). A segunda, contra hegemônica e de caráter socialista, tem como princípio a formação omnilateral do homem, ou seja, em todos os aspectos, a fim de que esse assuma o papel do ser crítico e emancipado (DELLA FONTE, 2018).

Sendo assim, frente ao caráter abrangente da ideologia dominante, a formação de professores é um dos pontos os quais são afetados por essa perspectiva a favor do capital. Nessa ótica, é cada vez mais comum observar eventos acadêmicos e científicos que apontam outros propósitos além de proporcionar a aquisição de novos conhecimentos. Propósitos esses cuja verificação permanece restrita aos indivíduos possuidores de criticidade. Dentre esses objetivos, é possível mencionar a mercantilização da educação.

Nesse sentido, esta pesquisa possui como objetivo geral investigar a relação estabelecida entre a execução de eventos acadêmicos e científicos e a mercantilização da educação. No que diz respeito aos objetivos específicos, é possível citar: expor situações as quais evidenciem a ideologia do capital presente na execução de um evento acadêmico e científico, e indicar pontos relevantes do evento os quais poderiam contribuir para a superação do docente acrítico e fragmentado pelo atual modo de produção capitalista. 
As perguntas de pesquisa que guiaram a investigação foram: 1) Qual é a relação estabelecida entre a execução de eventos acadêmicos e científicos e a mercantilização da educação? 2) Quais situações evidenciaram a ideologia do capital presente na execução de um evento acadêmico e científico? 3) Quais pontos relevantes do evento analisado poderiam contribuir para a superação do docente acrítico e fragmentado pelo atual modo de produção capitalista?

Além desta introdução, o presente artigo está dividido em três seções. Primeiramente, foram apresentadas as contribuições de autores acerca do embasamento teórico. Em seguida, a metodologia empregada no processo investigativo foi detalhada. Posteriormente, os dados coletados foram analisados e discutidos. Por fim, conclusões referentes ao estudo foram expostas.

\section{FUNDAMENTAÇÃO TEÓRICA}

Esta seção, que aborda a fundamentação teórica relevante para a construção do estudo, está dividida em duas subseções. Na primeira, foram apresentadas as definições e as características da aprendizagem flexível. Na segunda, o foco voltou-se para a análise da educação que é vista como uma mercadoria.

\subsection{A APRENDIZAGEM FLEXÍVEL}

Principalmente devido à crise do petróleo na década de 70, o regime de acumulação rígida, também conhecido como Taylorismo/Fordismo, decaiu no cenário da globalização patrocinada pelo capitalismo. Esse regime possuía como características principais a produção em larga escala, a padronização dos produtos e a existência de trabalhadores especializados em uma única função (RAMOS, 2014).

A partir do declínio do regime de produção anterior, o Toyotismo (ou regime de acumulação flexível) ganhou notoriedade no cenário mundial. Dentre suas características, é possível mencionar: produção estabelecida a partir da demanda, maior variedade de produtos disponíveis ao consumidor e presença de trabalhadores aptos a desempenharem diversas funções a fim de transitarem na cadeia produtiva (KUENZER, 2016).

No contexto do ensino e da aprendizagem, o regime de acumulação flexível proporcionou aos discentes e docentes a oportunidade de lidar com uma "[...] metodologia inovadora, que articula o desenvolvimento tecnológico, a diversidade de modelos dinamizadores da aprendizagem e as mídias interativas" (KUENZER, 2016, p. 1). Ainda de acordo com a mesma autora, 
profissionais, que pesquisam, trocam experiências e colaboram na solução de problemas, de forma aberta e constante (KUENZER, 2016, p. 1).

A aprendizagem flexível, bastante presente na educação a distância $(\mathrm{EaD})$, coloca o discente como ponto central do processo de aprendizagem pela instigação do "aprender a aprender". Além disso, é possibilitado a ele estudar quando e onde desejar. Por conseguinte, o processo exigirá mais comprometimento, iniciativa e disciplina estudantil.

\subsection{A EDUCAÇÃO COMO MERCADORIA}

Altamente sustentada pelas personificações do capital, a ideia apresentada à população acerca dos pontos positivos da aprendizagem flexível tem sido uma das estratégias para gerar lucro. Entretanto, o discurso por trás da concepção difundida traz uma ideologia compatível aos interesses do neoliberalismo.

Nesse sentido, como afirma Kuenzer (2016), o método é mais importante que o conteúdo a ser ensinado. Além disso, a aprendizagem flexível esconde relações de compra e venda de mercadorias, as quais resultam na emissão de certificados vazios de significado. Ou seja, os processos intelectuais empregados na obtenção desses são pouco complexos. Além disso, a aprendizagem flexível pressupõe percursos de aprendizagem homogêneos que raramente estimulam a criticidade do aprendente. Ademais, demonstra ser superficial à teoria, movimento chamado por Moraes (2003) de "recuo da teoria”. Nessas circunstâncias, muitas vezes, um certificado é adquirido por quem possui condições financeiras para comprá-lo.

Diante das mudanças impostas pela COVID-19, diversos setores da sociedade precisaram se adequar aos tempos de isolamento. Um desses setores é o da educação. Nesse contexto, é visível que novas dinâmicas passaram a fazer parte do universo educacional, dentre elas: gravação de videoaulas, realização de lives com especialistas em determinados temas educacionais e organização de eventos acadêmicos e científicos online. Esse último, ponto de análise deste artigo, muitas vezes mantém seus reais objetivos velados, mas estritamente vinculados à mercantilização da educação.

\section{METODOLOGIA}

Como postulado anteriormente, o objetivo geral desta pesquisa foi investigar a relação estabelecida entre a execução de eventos acadêmicos e científicos e a mercantilização da educação. No que tange aos objetivos específicos, é possível mencionar: expor situações que evidenciem a ideologia do capital presente na execução de um evento acadêmico e científico, assim como indicar pontos relevantes do 
evento os quais poderiam contribuir para a superação do docente acrítico e fragmentado pelo atual modo de produção capitalista.

No tocante às perguntas de pesquisa as quais guiaram essa investigação, menciona-se: a) Qual é a relação estabelecida entre a execução de eventos acadêmicos e científicos e a mercantilização da educação? b) Quais situações evidenciaram a ideologia do capital presente na execução de um evento acadêmico e científico? c) Quais pontos relevantes do evento analisado poderiam contribuir para a superação do docente acrítico e fragmentado pelo atual modo de produção capitalista?

Para desenvolver esta pesquisa de caráter qualitativo (SELIGER; SHOHAMY, 1989), foi necessário analisar o modo como foi organizado e conduzido um congresso internacional voltado para a área de educação. A fim de coletar dados, a autora deste estudo participou do evento como apresentadora de duas comunicações orais. Assim, o diário de campo foi utilizado como instrumento pesquisa. Nesse foram relatados, de forma detalhada, fatos observados relacionados ao evento. A coleta foi realizada em maio de 2020. Os dados coletados foram analisados a partir da interpretação e da comparação com a teoria postulada por autores referência na área estudada.

\section{ANÁLISE E DISCUSSÃO DE DADOS}

Esta seção está dividida em três subseções. Na primeira, foram apresentadas informações referentes ao congresso o qual foi alvo da análise. Na segunda, foram exibidos aspectos que evidenciaram a influência do discurso capitalista na organização e na condução do evento. Na terceira e última subseção, foram expostos pontos positivos acerca da realização de eventos acadêmicos e científicos nos moldes do congresso analisado, que embora sejam permeados por interesses capitalistas, podem contribuir para a superação do docente acrítico e fragmentado pelo atual modo de produção.

\subsection{O CONGRESSO}

O evento acadêmico científico analisado é um congresso internacional online na área de educação que ocorreu ao longo de três dias no mês de maio de 2020. O evento foi divulgado por meio das redes sociais e ofereceu aos participantes duas modalidades de participação: ouvinte ou apresentador de comunicação oral. Ainda, os participantes que optaram pela modalidade comunicação oral tiveram a oportunidade de publicar artigo científico como capítulo de livro em obra impressa e em ebook com ISBN.

Ainda em relação ao congresso, não houve interação entre os participantes do evento, uma vez que, a partir da aprovação do trabalho, cada participante deveria gravar um vídeo de apresentação da comunicação oral e fazer o upload desse em uma plataforma digital designada pela comissão organizadora. As gravações vieram a público no site do evento apenas nos dias de realização do 
congresso. Aos ouvintes, foi dada a possibilidade de acessar os vídeos de todas as apresentações de trabalho.

\subsection{O DISCURSO POR TRÁS DA IDEOLOGIA}

O discurso subjacente à realização do evento evidencia um viés capitalista no qual a quantidade de inscrições foi um fator mais primordial que qualidade dos trabalhos apresentados. Isso pôde ser visualizado a partir de indícios como a ampla divulgação do evento. Asism, com o auxílio de estratégias de marketing, foi amplamente exposta a concessão de certificados com carga horária elevada aos participantes.

Além do mais, a não delimitação de uma temática específica para o evento proporcionou um elevado número de inscritos. Assim, em comparação a um evento cuja temática é específica, em um evento abrangente, o número de inscrições, possivelmente, é maior. Consequentemente, também é maior o capital gerado aos organizadores do evento.

Ainda guiado pelo capital, o evento foi anunciado como um congresso de abrangência internacional. Isso elevou o valor das inscrições. Entretanto, a característica internacional não foi observada durante a execução do congresso. Ao final, o evento mostrou-se feito por e para pesquisadores brasileiros somente. Seu status internacional apenas culminou na inscrição de alto custo financeiro compatível apenas com um real evento de abrangência internacional. Porém, no caso do congresso analisado, o status aparente apenas velou seu caráter pseudo internacional.

\subsection{A BUSCA DA FORMAÇÃO OMNILATERAL A PARTIR DE CONTRADIÇÕES}

Embora o evento tenha manifestado interesses capitalistas como uma de suas motivações para realização, é possível verificar pontos positivos vinculados a essa modalidade de organização de evento.

A realização de eventos acadêmicos e científicos online, os quais utilizam-se da tecnologia como principal aliada, é válido e compatível com a situação de isolamento estabelecida pela pandemia da COVID-19. Assim sendo, um dos principais pontos positivos dessa modalidade é a aproximação entre pesquisadores distantes geograficamente unidos por um propósito prevalecente: aperfeiçoamento dos conhecimentos por meio da participação em eventos acadêmicos e científicos.

Além do mais, é inegável que diversas pesquisas apresentadas são de grande relevância na área de educação, inclusive, muitas são inéditas. Por isso, propiciam oportunidades de aprendizagem por meio de suas exposições, o que possivelmente poderia proporcionar insights aos ouvintes. Isso possivelmente os instigariam a desenvolver novas pesquisas a partir das perspectivas observadas e analisadas no congresso. 
Outra questão válida é a oportunidade de publicação acadêmica. No caso dos graduandos e graduados, essa oportunidade é ainda mais relevante, uma vez que grande parte das chamadas para publicação de artigos em capítulos de livros restringem a possibilidade aos pós-graduados, deixando os novos pesquisadores, representados por pesquisadores em início de carreira, em segundo plano.

A partir disso, verifica-se que a formação docente é permeada por ideologias as quais escondem seus verdadeiros objetivos. Cabe ao professor omnilateral identificar essas ideologias por meio de uma visão crítica que não permita a apropriação de sua consciência pelos discursos capitalistas da aprendizagem flexível, os quais tendem a mercantilizar a educação.

Em relação a isso, Mészáros (2008) afirma que, na busca por um projeto de sociedade igualitária que não seja guiada pelos discursos do capital, o professor precisa assumir um papel que possibilite a ele a não-alienação de sua consciência pelas personificações do capital. Em outras palavras, o docente contra hegemônico atua contra a internalização de ideais que asseguram os parâmetros reprodutivos do sistema capital.

Nesse contexto, as contradições do capital, ou seja, ações que são geradas pelo capitalismo, mas que podem ser utilizadas para sua própria superação, podem constituir uma possibilidade para a transformação do docente unilateral em ser omnilateral. Em outras palavras, a participação em eventos, como o analisado, embora contribua para a acumulação de capital, é passível de geração de pesquisas as quais possibilitem o aprimoramento da criticidade e da formação política.

\section{CONCLUSÃO}

Esse estudo evidenciou que o capitalismo está inserida de diversas formas na sociedade. Uma delas diz respeito à educação, mais especificamente, em oportunidades vinculadas à formação docente, como cursos de pós-graduação, cursos de formação inicial e continuada, cursos de aperfeiçoamento e eventos acadêmicos e científicos. Sendo assim, a ideologia do capital está presente na educação, independentemente de ocorrer em espaços formais ou não. No caso da realização de eventos acadêmicos e científicos online motivada pelas condições de isolamento social impostas pela pandemia da COVID-19, a mercantilização da educação tornou-se evidente.

Por meio da possibilidade de participação da autora deste estudo em um congresso internacional voltado para a área de educação, foram analisados aspectos relacionados à organização e à execução do referido evento. A partir disso, tornou-se claro que um dos objetivos para a condução desse foi a acumulação de capital. Entretanto, esse objetivo foi mascarado por alguns fatores, dentre eles: a oportunidade de divulgação de conhecimento e de publicação em livro impresso. Apesar disso, o evento apresentou pontos positivos. Esses poderão contribuir de modo significativo para a superação do docente acrítico e fragmentado pela ideologia do capitalismo. 
Desse modo, a mercantilização da educação corrobora a ideia de Mészáros (2008). O autor afirma que o capital, em sua forma cada vez mais destrutiva, propõe a "personificação das coisas e reificação das pessoas" (MÉSZÁROS, 2008, p. 90). Em outras palavras, há uma inversão de papéis. Assim, atingida por uma pseudo consciência, a sociedade passa a dar mais valor às mercadorias que aos próprios indivíduos.

Como afirma Mészáros (2008), a sociedade a ser alcançada visa à igualdade substancial, real, e não apenas formal, estabelecida por lei. Portanto, é necessário que haja uma transformação social emancipadora. Essa possui como ponto de partida a educação, não a educação tecnicista aligeirada e com qualidade dúbia fornecida às classes trabalhadoras cujo objetivo é unicamente preparar para o mercado de trabalho a fim de que o trabalhador seja produtor de mais-valia, mas sim a educação integral e emancipadora, que forma sujeitos críticos e omnilaterais, cuja força de trabalho não será dicotomizada em termos de trabalho manual e trabalho intelectual. 


\section{REFERÊNCIAS}

\section{REFERENCIAS}

DELLA FONTE, S. Formação no e para o trabalho. Educação Profissional e Tecnológica em Revista, Vitória, v. 2, n. 2, p. 6-19, 2018.

KUENZER, A. Trabalho e escola: a aprendizagem flexibilizada. Revista do Tribunal Regional do Trabalho da 10 $\mathbf{a}^{\mathbf{a}}$ Região, Brasília, v. 20, n. 2, p. 13-36, 2016.

MÉSZÁROS, I. A educação para além do capital. São Paulo: Boitempo, 2008.

MORAES, M. Iluminismo às Avessas: produção de conhecimento e políticas da formação docente. Rio de Janeiro: DP\&A, 2003.

MOURA, D. Trabalho e formação docente na educação profissional. Curitiba: Instituto Federal do Paraná, 2014.

RAMOS, M. História e política da educação profissional. Curitiba: Instituto Federal do Paraná, 2014.

SELIGER, H.; SHOHAMY, E. Second language research methods. Oxford: Oxford University Press, 1989. 